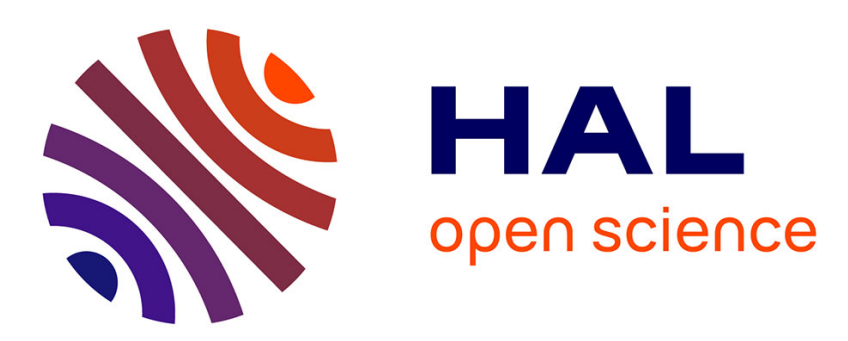

\title{
Inelastic coherent neutron scattering on TBBA in the low temperature phases
}

\author{
J. Doucet, M. Lambert, A.M. Levelut, P. Porquet, B. Dorner
}

\section{To cite this version:}

J. Doucet, M. Lambert, A.M. Levelut, P. Porquet, B. Dorner. Inelastic coherent neutron scattering on TBBA in the low temperature phases. Journal de Physique, 1978, 39 (2), pp.173-179. 10.1051/jphys:01978003902017300 . jpa-00208751

\section{HAL Id: jpa-00208751 https://hal.science/jpa-00208751}

Submitted on 1 Jan 1978

HAL is a multi-disciplinary open access archive for the deposit and dissemination of scientific research documents, whether they are published or not. The documents may come from teaching and research institutions in France or abroad, or from public or private research centers.
L'archive ouverte pluridisciplinaire HAL, est destinée au dépôt et à la diffusion de documents scientifiques de niveau recherche, publiés ou non, émanant des établissements d'enseignement et de recherche français ou étrangers, des laboratoires publics ou privés. 
Classification

Physics Abstracts

$61.30-63.20$

\title{
INELASTIC COHERENT NEUTRON SCATTERING ON TBBA IN THE LOW TEMPERATURE PHASES
}

\author{
J. DOUCET, M. LAMBERT, A. M. LEVELUT, P. PORQUET \\ Laboratoire de Physique des Solides (*) \\ Université Paris-Sud, Bâtiment 510, 91405 Orsay Cedex, France
}

B. DORNER

Institut Max-Von-Laue-Paul-Langevin, B.P. 156, 38042 Grenoble Cedex, France

(Reçu le 25 aô̂t 1977, révisé le 6 octobre 1977, accepté le 13 octobre 1977)

\begin{abstract}
Résumé. - Des expériences de diffusion inélastique de neutrons ont permis l'étude de la dynamique de réseau d'un monocristal de TBBA non deutérié ; ce monocristal se transforme par fusion en monodomaine smectique. En présence du bruit de fond incohérent, il a cependant été possible de déterminer plusieurs branches de dispersion des modes acoustiques longitudinaux et transverses pour les 3 phases cristalline (VIII), smectique B (V), smectique VI. Le mode transverse se propageant perpendiculairement aux couches de molécules n'a été observé que pour la phase cristalline $(0,15 \mathrm{THz}$ en bordure de zone) ; il n'a pas été résolu dans la phase smectique B ; l'expérience n'a pas été faite dans la phase VI.
\end{abstract}

\begin{abstract}
Inelastic coherent neutron scattering experiments have been performed on a nondeuterated single crystal of TBBA which is transformed by melting into a single smectic domain. Despite the strong incoherent background, it was possible to determine several acoustic longitudinal and transverse dispersion branches in three phases : solid (VIII), smectic B (V) and smectic VI. The transverse mode (rigid layer mode) propagating perpendicular to the layers of molecules has been observed in the solid phase ( $0.15 \mathrm{THz}$ at the zone boundary), while in the smectic B phase, this mode could no longer be resolved. The experiment was not performed for the smectic VI mesophase.
\end{abstract}

1. Introduction. - Terephtal-bis-butyl-aniline (TBBA) exhibits nine phases, at least five of which are mesomorphic [1].

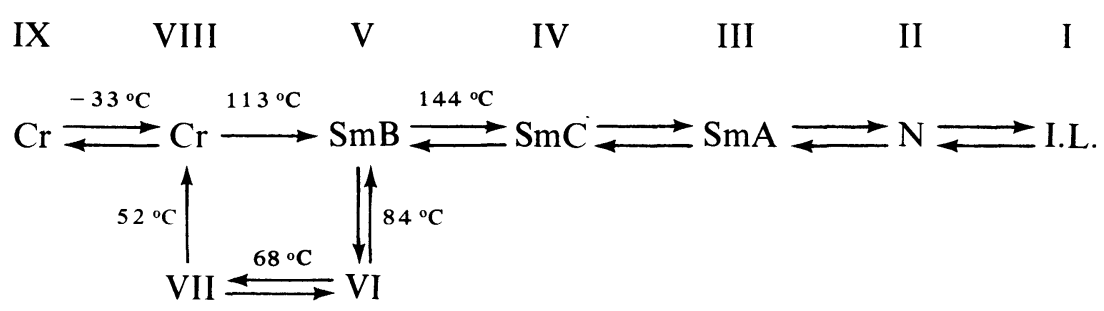

We know the structures of the phases $\mathrm{Cr}$ (VIII), $\mathrm{SmB}(\mathrm{V})$ and VI from X-ray scattering experiments $[1,2,3]$. Moreover, it is possible to obtain monodomain samples of SmB and VI, if we start from a single crystal at room temperature, by successive melting $\left(113^{\circ} \mathrm{C}\right)$ and cooling down. The structures of the phases SmB and VI are more or less crystal-like : a three-dimensional lattice can be defined (Fig. 1); but

(*) Associé au C.N.R.S. there are fluctuations of large amplitude about the mean positions (the thermal agitation factor is very high).

- The smectic B phase (monoclinic with a centered face $(a, b)$ parallel to the smectic layer plane) looks like a plastic crystal in which the molecules undergo orientational jumps around their long axis with six or twelve equivalent positions $[4,5]$. The random rotational orientations allow an almost hexagonal order in a plane perpendicular to the long axis. The 

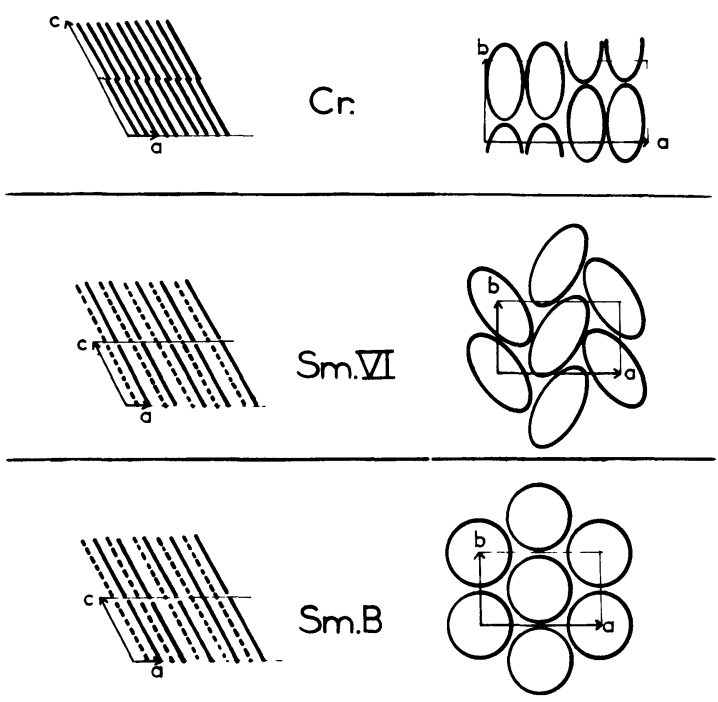

FIG. 1. - Schematic description of the structures of the 3 studied phases by their projections on the $(a, c)$ and $(a, b)$ planes; notice the difference of scale between the two projections. In the case of the $(a, c)$ projection, molecules are represented by full lines when located at $y=0$ and dotted lines for $y=1 / 2$.

molecules are tilted with respect to the layers by the monoclinic angle of $122^{\circ}$ at $115^{\circ} \mathrm{C}$.

- In phase VI, the $(a, b)$ face, parallel to the layer plane, is no longer centered. The orientations of the molecules are now ordered. In each layer, the packing is herring-bone like, similar to the SmE structure [6] : $180^{\circ}$ jumps around the long axis are still allowed by symmetry and such a motion seems to have been observed by inelastic neutron scattering experiments [7].

In fact, clusters of herring-bone packing have been observed even in the $\mathrm{SmB}$ phase, but with a correlation length of about five unit cells [4]. To describe the pseudo-hexagonal symmetry of $\mathrm{SmB}$, one needs three different orientations (with axes at $2 \pi / 3$ ) for the herring-bone domains which are distributed at random.

For such plastic-crystal-like structures, it is an interesting question whether defined acoustic phonons exist in the whole Brillouin zone specifically for the transverse modes. De Gennes and Sarma [8] proposed an alternative model for the smectic B phase. They suggest that the melting of the terminal aliphatic chains induces the crystal-smectic B transition by weakening the interaction between layers such that the corresponding transverse mode becomes purely viscous and the shear constant goes to zero. Nevertheless recent measurements of the velocity of ultrasonic transverse waves in some compounds $(\mathrm{SmB}$ and $\mathrm{SmE}$ with molecules oriented perpendicular to the layer) show that the sound velocity has a finite value at long wavelength in a direction perpendicular to the layer plane [9]. For these reasons, we have tried to observe collective excitations in the three different phases.
Neutron scattering from collective motions in a liquid crystal has so far only been performed in the nematic phase [10]. Similar studies in smectic phases are severely hampered by the difficulty of obtaining large single domain samples. The choice of the compound TBBA for these first experiments is justified by the fact that we have a good knowledge of the mean and local structures and by its relative aptitude to give large single crystals. The structure is monoclinic in all three phases, however, rendering the dynamics not simple at all.

2. Experiment. - Inelastic neutron scattering experiments have been performed at the ILL on the threeaxes spectrometer IN2 with pyrolitic graphite as monochromator and analyser. To obtain good resolution, we worked at small energies $E_{0}=1.20 \mathrm{THz}$ $(\lambda=4.05 \AA)$ with a Be-filter in front of the sample to reduce the higher order contamination. Improving the resolution also means improving the ratio of the coherent signal over the incoherent background. The reason is that the incoherent background is proportional to the 4-dimensional volume of the resolution function in the space of momentum transfer $\mathbf{Q}$ and energy transfer $h v$, while the coherent signal from a dispersion surface is only proportional to the three dimensions in $\mathbf{Q}$ and has, ideally, a $\delta$-function for the energy transfer. Thus, reducing the volume of the resolution function increases the ratio of signal to background like the ratio of surface to volume. The sample was mounted in an evacuated oven, heated primarily by an oil bath thermostat controlled by a small electrical heater.

Large single crystals $10 \times 20 \times 2 \mathrm{~mm}^{3}$ of nondeuterated TBBA were grown from a chloroform solution in the Laboratoire de Physique Cristalline d'Orsay by Prof. J. P. Chapelle in collaboration with J. L. Godart. Before any heating of the sample, its mosaic width $\left(^{1}\right)$ was smaller than one degree. Table I gives the lattice parameters and space groups for the three phases studied ( $c$ is parallel to the molecular axis and $b$ is the twofold axis). The three structures are sufficiently similar for no twinning to take place by

\section{TABLE I}

Unit cell parameters, density and space group for the three studied phases of TBBA

\begin{tabular}{|c|c|c|c|c|c|c|c|}
\hline Phase & $\begin{array}{l}a \\
\AA\end{array}$ & $\begin{array}{l}b \\
\AA\end{array}$ & $\begin{array}{l}c \\
\AA\end{array}$ & $\beta$ & $\rho$ & $\begin{array}{l}\text { Space } \\
\text { group }\end{array}$ & $\begin{array}{l}\text { Multi- } \\
\text { plicity }\end{array}$ \\
\hline - & - & - & - & - & - & - & - \\
\hline Crystal & 17.57 & 5.75 & 53.2 & $115,5^{\circ}$ & 1.08 & A2/a & 8 \\
\hline VI & 10.38 & 5.24 & 28.31 & $123,6^{\circ}$ & 1.02 & $\mathrm{~Pa}$ & 2 \\
\hline $\mathrm{mB}$ & 10.15 & 5.18 & 28.6 & $119^{\circ}$ & 1.01 & $\mathrm{C} 2 / \mathrm{m}$ & 2 \\
\hline
\end{tabular}

( $\left.{ }^{1}\right)$ The mosaic width is approximatively isotropic in the $\left(a^{*}, b^{*}\right)$ plane. 

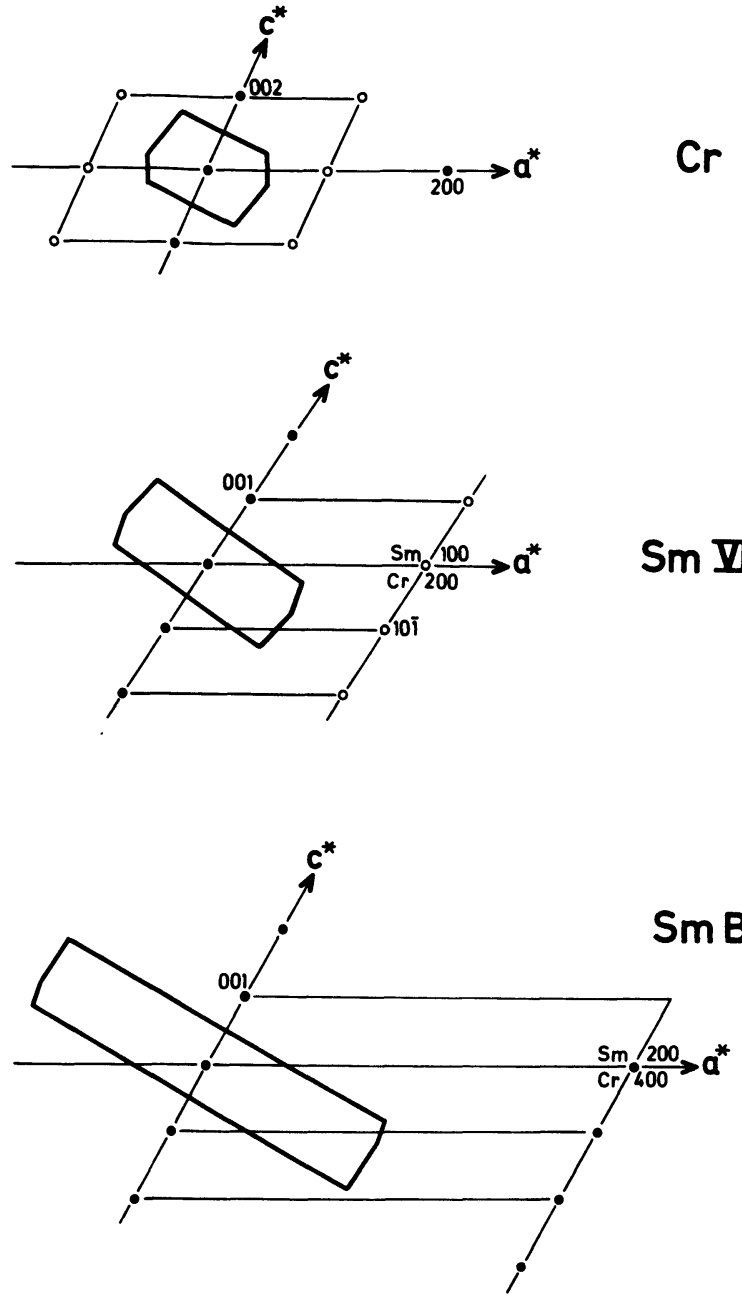

Cr
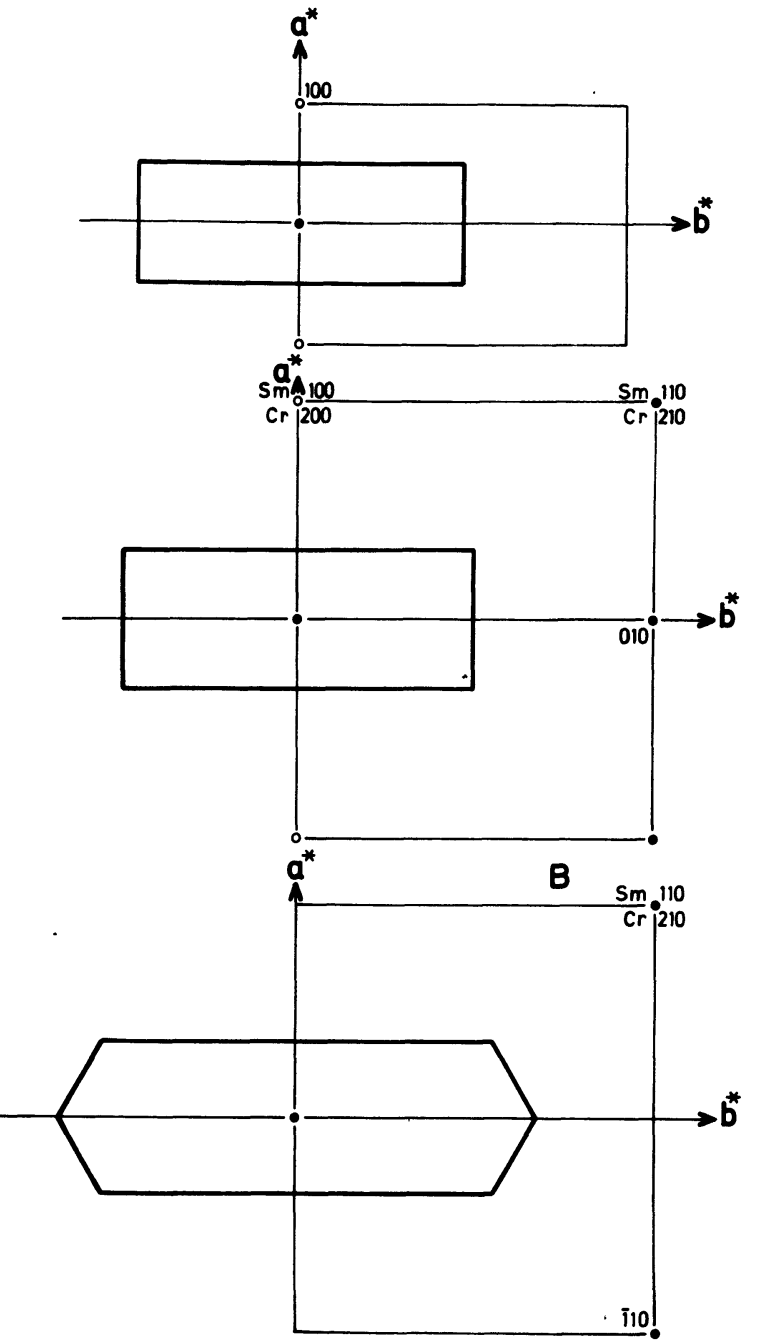

Fig. 2. - Sections of the Brillouin zone in the $\left(a^{*}, c^{*}\right)$ and $\left(a^{*}, b^{*}\right)$ planes for the three phases. Open circles represent forbidden reflections due to the glide mirror in the crystalline and Sm VI structures.

going through the phase transformation from solid to $\mathrm{SmB}$ and to VI. However, it is impossible to come back to a single crystal in the solid phase. Cooling phase VI, the sample breaks in the phase transformation to the solid. Therefore successive measurements were performed for different phases in one temperature cycle. We used two samples with two different orientations, first $a^{*}$ and $c^{*}$ in the scattering plane and then $a^{*}$ and $b^{*}$. Figure 1 gives schematically the packing of the molecules and figure 2 the Brillouin zones for the three phases and the two orientations. A detailed description of the structures has been published earlier [1, 2, 3].

The point group is the same for the three phases $(2 / \mathrm{m})$ which gives thirteen non-vanishing elastic constants. Acoustic modes with a wave vector parallel to the twofold axis ( $b^{*}$-axis) are purely transverse or longitudinal; those with a wave vector in the mirror plane $\left(a^{*}, c^{*}\right)$ have mixed transverse [11]. longitudinal eigenvectors for amplitudes in the mirror plane but are purely transverse for amplitudes perpendicular to the mirror.

The intensity of coherent inelastic scattering from mode s of energy $v_{\mathrm{s}}$ is given by $\left({ }^{2}\right)$ :

$$
S_{\mathrm{s}}(\mathbf{Q}, v) \simeq\left|G_{\mathrm{s}}(\mathbf{Q})\right|^{2} \cdot F_{\mathrm{s}}\left(v, v_{\mathrm{s}}(\mathbf{q}), T\right)
$$

where $G_{\mathrm{s}}$ is the inelastic structure factor

$$
G_{\mathbf{s}}(\mathbf{Q})=\sum_{j}^{\text {unit cell }} \frac{b_{j}}{\sqrt{M_{j}}} \mathrm{e}^{-W_{j}}\left(\mathbf{Q} \cdot \boldsymbol{\sigma}_{\mathbf{s}}^{j}(\mathbf{q})\right) \mathrm{e}^{i \mathbf{Q} \mathbf{R}_{j}}
$$

$b_{j}$ and $M_{j}$ are the coherent scattering length and the mass of atom $j$ and $\mathbf{R}_{j}$ is its position in the unit cell, $\mathrm{e}^{-\boldsymbol{w}_{j}}$ is the Debye-Waller factor and $\boldsymbol{\sigma}_{\mathrm{s}}^{j}(\mathbf{q})$ the amplitude of atom $j$ in the mode $s$ at phonon wave vector $\mathbf{q}$.

( $\left.{ }^{2}\right)$ See for example : B. Dorner, R. Comès, Dynamics of Solids and Liquids by Neutron Scattering, Topics in Current Physics (Springer-Verlag), 1977. 


\section{TABLE II}

Characteristics of the observed modes

Wector $\begin{gathered}\text { Wave- } \\ \text { vector } \\ b^{*}\end{gathered} \quad \begin{gathered}\text { LA observed in the three } \\ \text { phases } \\ \text { TA observed in the three } \\ \text { phases } \\ \text { TA seen only in the crys- } \\ \text { talline phase }\end{gathered}$

$F_{\mathrm{s}}$ gives the intensity distribution with energy transfer $v$. The integral over $v$ for $h v_{\mathrm{s}} \ll k T$ gives :

$$
\int_{v} F_{\mathrm{S}}\left(v, v_{\mathbf{s}}(\mathbf{q}), T\right) \mathrm{d} v \sim \frac{T}{v_{\mathbf{s}}^{2}(\mathbf{q})} .
$$

For small $|q|$ (long wavelength) acoustic phonons the $\sigma_{\mathbf{s}}^{j}(q)$ are the same for all atoms $j$. From eq. (2) we see then that the intensity of small $|q|$ acoustic phonons is scaled with the structure factor of the corresponding Bragg peak. Thus, it is the existence of strong Bragg peaks (400) and $(211)\left({ }^{3}\right)$ for the crystalline phase, (200) and (110) for the other phases, which allowed us to observe the coherent phonon signal on top of the incoherent background. Table II gives the direction of the wave vector and the main polarization vectors (e.g. $a^{*}$ polarization is perpendicular to $b^{*}$ and has the major component in the $a^{*}$ direction), for the different modes we have studied.

3. Results. - 3.1 Modes PROPAGATING IN A DIRECTION PERPENDICULAR TO THE LAYER PLANES. - Only one mode has been studied in this direction with a more or less transverse polarization vector, see figure $3 a$ (there was no strong Bragg peak to study the longitudinal mode). This mode corresponds to a glide motion of the layers relative to each other. The measured dispersion $\left({ }^{4}\right)$ is shown in figure $3 b$. The slope of the dispersion curve gives a sound velocity of $750 \mathrm{~m} . \mathrm{s}^{-1}$ at room temperature. The frequency decreases slightly with increasing temperature. The molecular motion at the Brillouin zone boundary corresponds to a polarization vector, for which neighbouring layers have opposite amplitudes. These rigid layer shear modes at room temperature appear to have a frequency of $0.15 \mathrm{THz}$ at the Brillouin zone boundary.

These modes could no longer be resolved in the SmB phase. However constant- $q$ scans, see figure 4,

$\left({ }^{3}\right)$ The reflexion (210) is missing in the crystalline phase.

$\left({ }^{4}\right)$ No deconvolution has been done on the phonon curve data.
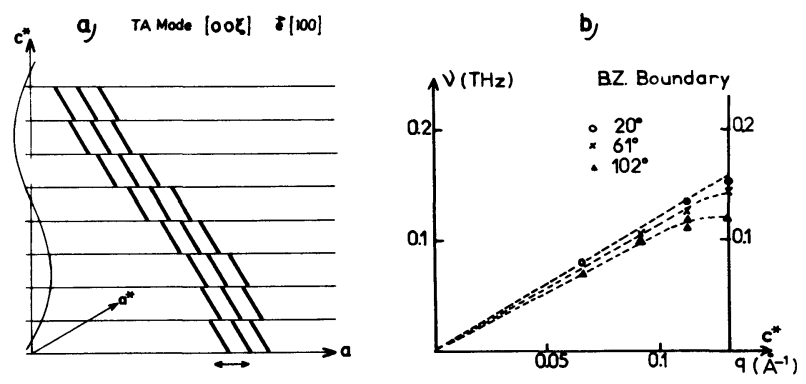

FIG. 3. - a) Schematic representation of the molecular motions for the shear mode propagating in the $c^{*}$ direction with a polarization parallel to $a^{*} . b$ ) Dispersion curve of this mode for the crystalline phase.

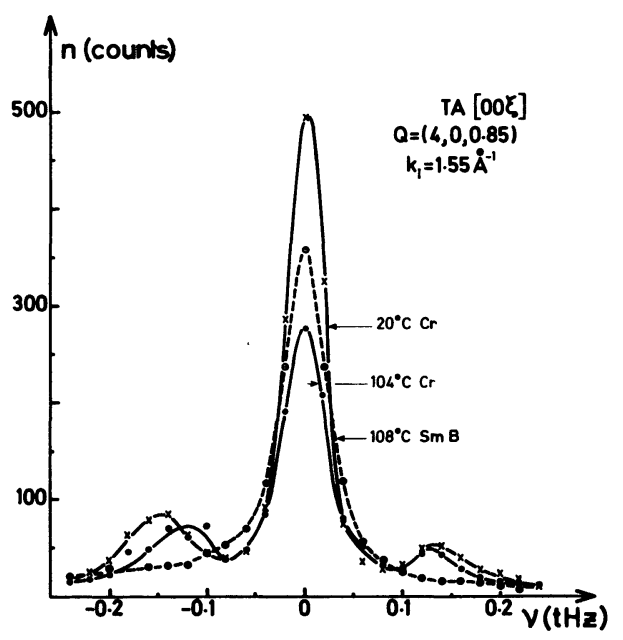

FIG. 4. - Constant $q$ scans at the point $(4,0,0.85)$ for the crystalline phase $((2,0,0.426)$ for the smectic $B$ phase $)$ performed in order to study the rigid layer shear mode.

show that the quasielastic intensity in $\mathrm{SmB}$ at $108{ }^{\circ} \mathrm{C}$ is considerably higher than in the solid at $104{ }^{\circ} \mathrm{C}$ : the major part of the intensity at $v=0$ is certainly incoherent elastic scattering; the decrease in intensity between $20^{\circ} \mathrm{C}$ and $104^{\circ} \mathrm{C}$ is partly due to an increase 
of the thermal agitation. The additional intensity at $108{ }^{\circ} \mathrm{C}$ is very probably inelastic (quasielastic) in nature. It may originate from a low frequency damped or overdamped phonon or from a diffusive gliding of layers with a relaxation time. Ultrasonic velocity measurements of this shear mode in other compounds [9] have shown a strong decrease of the sound velocity going from the solid to the SmB phase, but the sound velocity stayed finite in SmB. These effects will be studied in more detail with neutron scattering on a fully deuterated sample in the near future.

3.2 MODES WITH A WAVE-VECTOR PERPENDICULAR TO THE LONG MOLECULAR AXES. - Four different phonon branches have been investigated with wavevector and polarization either parallel to $a^{*}$ or $b^{*}:$ the results are given in figure 5 and figure 6 together with a schematic description of the molecular motions corresponding to the different excitations. The dispersion curves were relatively easy to determine for the 3 different phases and for both longitudinal and transverse polarizations. However, the modes could not be followed completely up to the Brillouin zone
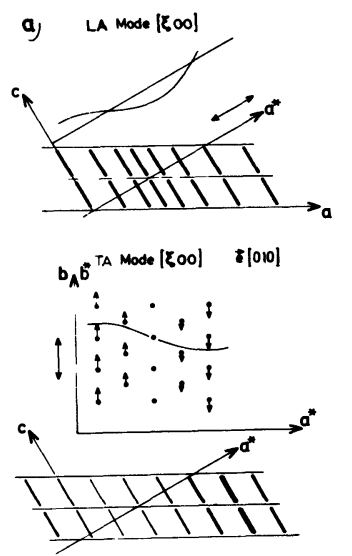

b)

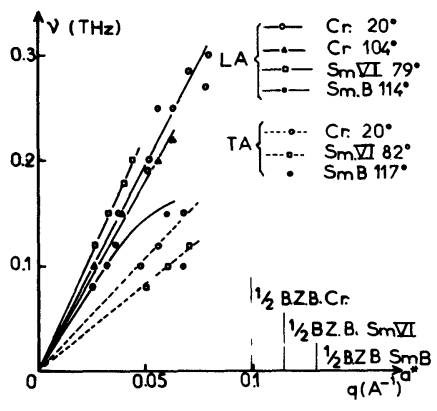

Fig. 5. - a) Schematic representation of the molecular motions for the longitudinal (LA) and transverse (TA polarized in the $b^{*}$ direction) modes propagating in the $a^{*}$ direction. $b$ ) Dispersion curves of these modes.

boundary, even for the solid phase; the signal became too weak and smeared out in the background; from equations (1) and (3), we understand that the intensity is proportional to $v_{\mathrm{s}}^{-2}$ and consequently becomes weaker when the distance to the zone centre increases. For the smectic phases, where the molecular motion increases, the influence of the Debye-Waller factor certainly becomes more important and the signal is much reduced; moreover, the rotational diffusion of the molecules in SmB, as well as changes in the molecular conformation (NMR experiments give an evidence of such deformations [12]), may give rise to considerable damping of the observed excitations : the
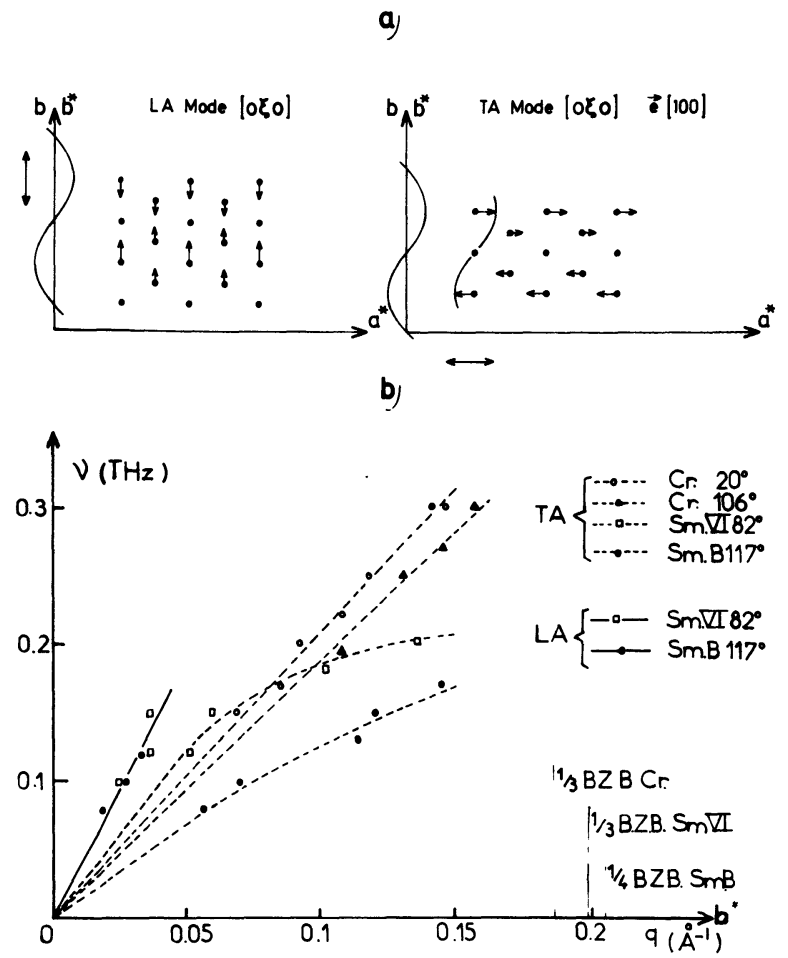

FIG. 6. - a) Schematic representation of the molecular motions for the longitudinal (LA) and transverse (TA polarized in the $a^{*}$ direction) modes propagating in the $b^{*}$ direction. $b$ ) Dispersion curves of these modes.

observed neutron groups corresponding to these excitations would broaden and disappear for even smaller $q$ values than in the solid phase. Similar effects have already been reported for plastic crystals [13]. All the observed dispersion curves are represented in figures $5 b$ and $6 b$; only the following acoustic modes remain unstudied :

- the longitudinal modes polarized in the $b$ direction in the solid phase : they should be visible near the 211 diffraction spot but were not investigated during this set of experiments ;

- the transverse modes polarized along $b$ and propagating in the $a^{*}$ direction in the case of SmB : this mode is difficult to detect because of the low symmetry of the structure; in most directions of observation both LA and TA modes are visible. Figures 7 and 8 give the results of several constant energy scans performed in order to observe respectively the LA and TA modes propagating in the $a^{*}$ direction. The neutron groups are well resolved in figure 7 (LA) while the curves seem more complex in figure 8. These last scans correspond to experiments performed in a geometry where both the TA and LA modes can be detected; as the LA modes are known from experiments performed in a different geometry (Fig. 7), the two peaks visible in figures $8 b$ and $8 c$ for the smectic VI phase are easy to identify. These two peaks are not resolved for the SmB modification : the observed single peak is broader than for the Sm VI phase and its position does 


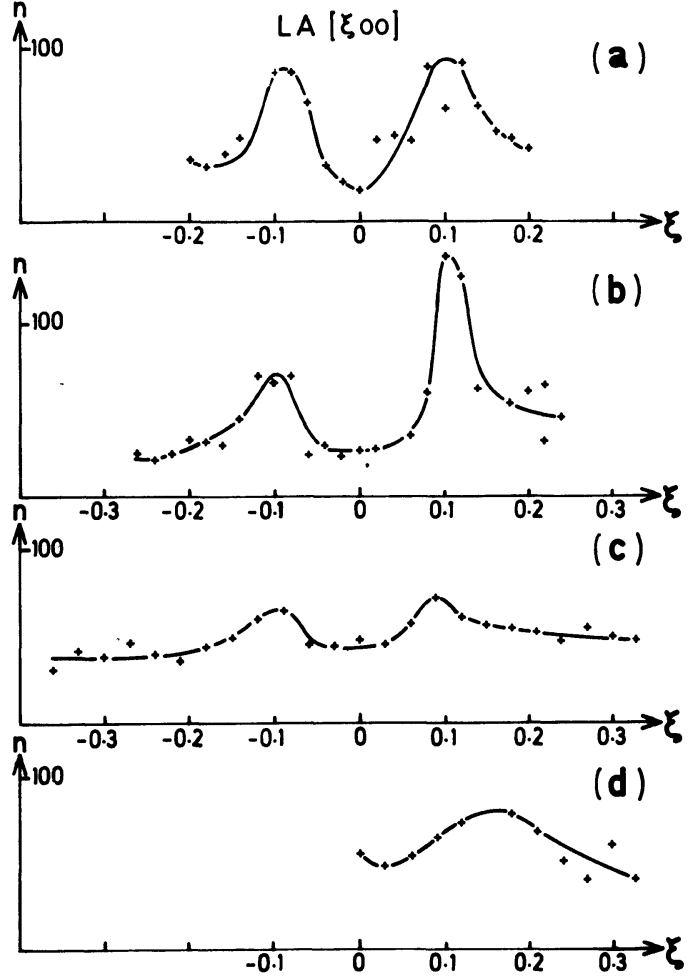

Fig. 7. - Constant energy scans $(v=0.15 \mathrm{THz})$ performed close to the (400) reflection of the crystal ((200) for the smectic phases) in order to study the longitudinal excitations with wave-vector parallel to $a^{*}$; the momentum transfer $\xi$ is given on a reduced scale corresponding to the crystalline structure. a) Crystal $20^{\circ} \mathrm{C}$; b) Crystal $104^{\circ} \mathrm{C}$; ) Sm VI $79^{\circ} \mathrm{C}$; d) Sm B $114^{\circ} \mathrm{C}$.

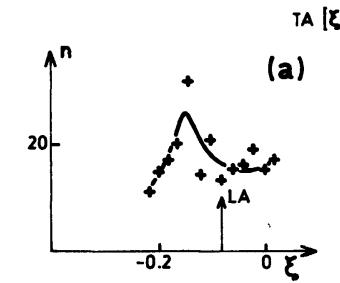

$A[\xi 00] \quad: 010]$
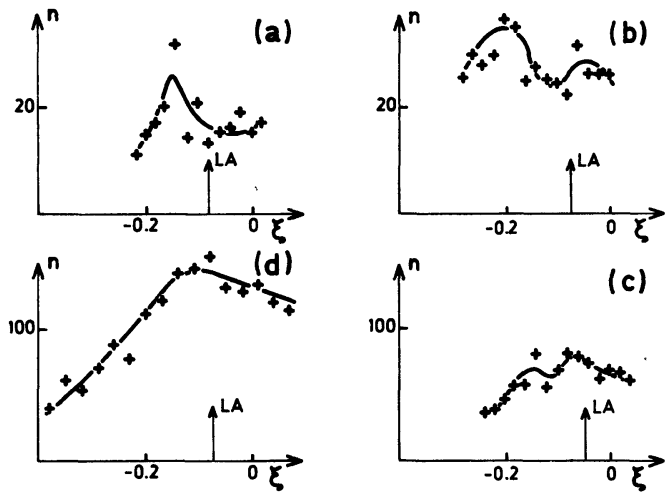

FIG. 8. - Constant energy scans performed close to the (211) reflection for the crystal and (110) reflection for the smectic phases in order to study the transverse excitations with wave-vector parallel to $a^{*}$ (polarization along $b$ ). The previously measured frequency of the corresponding longitudinal mode is given for each scan (LA). a) Crystal $\left.20^{\circ} \mathrm{C}-v=0.12 \mathrm{THz} ; b\right)$ Sm VI $82^{\circ} \mathrm{C}-v=0.12 \mathrm{THz}$; c) $\mathrm{Sm}$ VI $\left.82^{\circ} \mathrm{C}-v=0.08 \mathrm{THz} ; d\right) \mathrm{Sm} \mathrm{B} 117^{\circ} \mathrm{C}-v=0.08 \mathrm{THz}$.

not fit with the previously observed longitudinal branch, indicating that the transverse excitations actually exist with an energy lower than the energy of the corresponding point in the longitudinal branch.
From these experimental results, we can conclude that the energy of these transverse excitations has the same order of magnitude for the two smectic phases but a precise dispersion curve cannot be established for the SmB modification. It can also be observed on figure $8 a$ that only the peak corresponding to the transverse excitations is apparent and well-defined as far as the solid phase is concerned.

From the initial slopes of all the observed dispersion curves, sound velocities were derived. They are listed in table III. Due to the low symmetry of the structure only two elastic constants, corresponding to displacements in the twofold axis direction, could be derived, $C_{22}$ and $C_{66}$, and are given in table III. (The density of each phase, $\rho$, was deduced from the lattice parameters in table I.) If we consider the three different phases, two observations can be made :

- the sound velocity $\left({ }^{5}\right)$ is always smaller for the smectic B modification : such a result can be expected from the knowledge of the successive transformations and the structures of the three phases;

- the modes with main polarization along $a^{*}$, either longitudinal (Fig. 5b) or transverse (Fig. 6b), have the highest sound velocity in the Sm VI phase. This is rather unexpected but is probably a consequence of the herring-bone packing of the Sm VI phase (Fig. 1).

4. Conclusion. - Using neutron inelastic scattering experiments, the dynamics of a single domain sample of non-deuterated TBBA has been investigated. Despite the strong incoherent background coming from the hydrogen content of the material, we have shown that useful information on the low energy acoustic phonons could be obtained : this is due to the good resolution of the IN2 spectrometer of I.L.L.

The results represent the most complete study of this kind performed for smectic mesophases. Most of the phonon branches investigated were observed for the three different phases, crystal, Sm VI, SmB, whatever their polarization. It can be noticed particularly that the transverse modes, at least with a wave-vector perpendicular to the molecular direction, are well defined for the two ordered smectic phases which appear indistinguishable from plastic crystals. The shear-wave, with wave-vector normal to the layers, has yet not been observed for the SmB phase (no experiment was performed for the Sm VI modification); only an increase in the quasi-elastic scattering was detected. Further experiments will be necessary to give a more complete description of the dynamics of these phases : they are planned on deuterated single domain samples with the purpose of getting more precise and extensive results about the dispersion curves.

${ }^{(5)}$ By ultrasonic experiments, similar sound velocities have been measured in other $\mathrm{SE}_{\mathrm{A}}$ and $\mathrm{SB}_{\mathrm{A}}$ phases [9]. 
TABLE III

Sound velocities and elastic constants

\begin{tabular}{|c|c|c|c|c|c|}
\hline Wave-vector & $\begin{array}{l}\text { LA } \\
a^{*}\end{array}$ & $\begin{array}{l}\text { TA } \\
a^{*}\end{array}$ & $\begin{array}{l}\text { LA } \\
b^{*}\end{array}$ & $\begin{array}{l}\text { TA } \\
b^{*}\end{array}$ & $\begin{array}{l}\text { TA } \\
c^{*}\end{array}$ \\
\hline Polarization & $a^{*}$ & $b^{*}$ & $b^{*}$ & $a^{*}$ & $a^{*}$ \\
\hline Solid $20^{-}$ & - & - & - & - & - \\
\hline $\begin{array}{l}\text { Velocity } \mathrm{ms}^{-1} \\
\text { Elastic cte } \mathrm{Nm}^{-2}\end{array}$ & $2500 \pm 200$ & $1350 \pm 130$ & & $\begin{array}{c}1300 \pm 100 \\
C_{66}+0.18 \times 10^{10}\end{array}$ & $750 \pm 70$ \\
\hline $\begin{array}{l}\text { Solid } 104^{\circ} \\
\text { Velocity } \mathrm{ms}^{-1} \\
\text { Elastic cte } \mathrm{Nm}^{-2}\end{array}$ & $2300 \pm 250$ & & & $\begin{array}{c}1200 \pm 100 \\
C_{66}=0.16 \times 10^{10}\end{array}$ & $680 \pm 70$ \\
\hline $\begin{array}{l}\mathrm{SmB} 115^{\circ} \\
\text { Velocity } \mathrm{ms}^{-1} \\
\text { Elastic cte } \mathrm{Nm}^{-2}\end{array}$ & $2100 \pm 400$ & & $\begin{array}{c}2360 \pm 250 \\
C_{22}=0.56 \times 10^{10}\end{array}$ & $\begin{array}{c}900 \pm 180 \\
C_{66}=0.08 \times 10^{10}\end{array}$ & \\
\hline $\begin{array}{l}\text { Sm VI } 80^{\circ} \mathrm{C} \\
\text { Velocity } \mathrm{ms}^{-1} \\
\text { Elastic cte } \mathrm{Nm}^{-2}\end{array}$ & $2800 \pm 300$ & $1050 \pm 150$ & $\begin{array}{c}2360 \pm 250 \\
C_{22}=0.57 \times 10^{10}\end{array}$ & $\begin{array}{c}1530 \pm 150 \\
C_{66}=0.24 \times 10^{10}\end{array}$ & \\
\hline
\end{tabular}

From the present study, values of the sound velocity, for different propagation directions and polarizations, can already be derived and some elastic constants have been measured. In addition to the above results, it may be pointed out that a search for the optical low frequency zone centre mode, previously observed at $0.65 \mathrm{THz}$ by Raman scattering [14], has been attempted with a negative result. This mode is probably drowned in the incoherent background, due to its large damping at room temperature; it should

be rendered more visible by cooling the sample at lower temperatures [15].

Acknowledgments. - We thank Prof. J. P. Chapelle and J. L. Godart for the preparation of the very good single crystals of TBBA, which we had to break at the end of our work ; Dr. L. Liebert for the synthesis of the large quantity of compound which was used and P. Flores for his continuous assistance during the experiment and help with the oven.

\section{References}

[1] Doucet, J., Mornon, J. P., Chevallier, R., Lifchtiz, A., Acta Crystallogr. B 33 (1977) 1701.

[2] Doucet, J., LeVelut, A. M., Lambert, M., Mol. Cryst. Liq. Cryst. 24 (1973) 317.

[3] Doucet, J., Levelut, A. M., Lambert, M., Phys. Rev. Lett. 32 (1974) 301.

[4] Levelut, A. M., J. Physique Colloq. 37 (1976) C3-51.

[5] Hervet, H., Volino, F., Dianoux, A. J., Lechner, R. E., J. Physique Lett. 35 (1974) L-151.

[6] Doucet, J., Levelut, A. M., LAMbert, M., Liebert, L., Strzelecki, L., J. Physique Colloq. 36 (1975) Cl-13.

[7] Volino, F., Dianoux, A. J., Hervet, H., J. Physique Colloq. 37 (1976) C3-55.
[8] De Gennes, P. G., Sarma, G., Phys. Lett. A 38 (1972) 219.

[9] Ünal, H., BaCRI, J. C., J. Physique Lett. 38 (1977) L-111.

[10] Conrad, H. M., Stiller, H. H., StockmeYer, R., Phys. Rev. Lett. 36 (1976) 264.

[11] Fedorov, P. J., Theory of elastic waves in crystals, New York (Plenum Press) 1968.

[12] Charvolin, J., Deloche, B., J. Physique Colloq. 37 (1976) C3-69.

[13] Stirling, W. G., Press, W., Stiller, H. H., J. Phys. in press.

[14] SCHnuR, J. M., Fontana, M., J. Physique Lett. 35 (1974) L-53.

[15] Fontana, M. P., Bini, S., Phys. Rev. A 14 (1976) 1555. 